\title{
PENGARUH MUTU PELAYANAN DOKTER DAN PHYSICAL EVIDANCE TERHADAP LOYALITAS PASIEN RAWAT INAP
}

\author{
Abidah Ismail Lubis \\ Fakultas Kesehatan Masyarakat Universitas Sumatera Utara, Indonesia \\ Email: drabidahismail@gmail.com
}

\begin{abstract}
Abstrak
Rumah Sakit Umum Sarah Medan dalam beberapa tahun belakangan menghadapi masalah penurunan tingkat loyalitas pasien. Mutu pelayanan dokter dan physical evidence merupakan faktor-faktor yang dinilai berkontribusi besar terhadap kepuasan pasien dan loyalitas pasien. Jenis penelitian yang digunakan adalah survei kuantitatif, dengan menggunakan pendekatan potong lintang (cross sectional). Penelitian ini dilaksanakan di RSU Sarah Medan. Populasi dalam penelitian ini adalah pasien yang menjalani rawat inap, dengan jumlah sampel sebanyak 82 orang. Metode analisis data dalam penelitian ini adalah dengan menggunakan analisis regresi logistik. Dari hasil analisis multivariat menunjukkan bahwa variabel mutu pelayanan dokter $(\mathrm{p}=0,001)$ dan physical evidence rumah sakit $(\mathrm{p}=0,004)$ terbukti berpengaruh terhadap loyalitas pasien. Disarankan bagi RSU Sarah Medan agar terus mengevaluasi kinerja pelayanan dokternya, seperti bersikap profesional dan bekerja sesuai dengan standar operasional yang telah ditetapkan sehingga semakin meningkatkan kepercayaan pasien untuk memanfaatkan fasilitas pelayanan kesehatan di RSU Sarah Medan. Begitu juga terkait physical evidence rumah sakit, Untuk terus dibenahi agar meningkatkan rasa kepuasan para RSU Sarah Medan dan mau kembali menggunakan jasa pelayanan kesehatan di RSU Sarah Medan.
\end{abstract}

Kata Kunci: mutu pelayanan dokter; physical evidence; loyalitas pasien

\section{Abstract}

In recent years, Sarah Medan General Hospital has faced the problem of decreasing patient loyalty. The quality of doctor's service and physical evidence are factors that are considered to have contributed greatly to patient satisfaction and patient loyalty. This type of research is a quantitative survey, using a cross sectional approach. This research was conducted at the Sarah Medan Hospital. The population in this study were patients who were hospitalized, with a total sample of 82 people. The data analysis method in this research is to use logistic regression analysis. The results of the multivariate analysis showed that the variable quality of doctor services $(p=0.001)$ and physical evidence of the hospital $(p=0.004)$ proved to have an effect on patient loyalty. It is recommended for Sarah Medan Hospital to continue to evaluate the performance of its doctor services, such as being professional and working in accordance with established operational standards so as to increase patient confidence in utilizing health care

$\begin{array}{ll}\text { How to cite: } & \text { Lubis. A. I. (2021) Pengaruh Mutu Pelayanan Dokter dan Physical Evidance Terhadap Loyalitas Pasien } \\ & \text { Rawat Inap. Syntax Literate: Jurnal Ilmiah Indonesia, 7(1). http://dx.doi.org/10.36418/syntax- } \\ & \text { literate.v7i1.1859 } \\ \text { E-ISSN: } & 2548-1398 \\ \text { Published by: } & \text { Ridwan Institute }\end{array}$


facilities at Sarah Medan Hospital. Likewise with the physical evidence of the hospital, to continue to be improved in order to increase the sense of satisfaction of the Sarah Medan Hospital and want to return to using health services at Sarah Medan Hospital.

Keywords: doctor's service quality; physical evidence; patient loyalty

Received: 2021-12-20; Accepted: 2022-01-05; Published: 2022-01-15

\section{Pendahuluan}

Dalam beberapa tahun terakhir bisnis pada sektor pelayanan kesehatan khususnya rumah sakit di Indonesia telah berkembang sangat pesat (Trisnantoro, 2018). Hal ini dapat dilihat dari munculnya berbagai rumah sakit swasta di kota-kota besar hingga ke pelosok daerah dengan berbagai model yang ditawarkan, ada yang bersifat individual, rumah sakit jaringan, hingga rumah sakit yang berlabel internasional.

Mutu pelayanan dirumah sakit merupakan suatu fenomena yang unik, sebab dimensi dan indikatornya dapat berbeda-beda diantara orang yang terlibat dalam pelayanan kesehatan (Arianto, 2017). Loyalitas pasien merupakan aspek yang sangat sensitif yang harus diperhatikkan karena menyangkut persepsi personal individu pasien, jika pasien merasa senang dan puas dengan pelayanan yang diberikan tentu menimbulkan perasaan yang positif (Supriyatna, 2016).

Bisnis layanan kesehatan seperti rumah sakit sangat membutuhkan keseriusan dalam penanganannya, bahkan rumah sakit harus berkapasitas sempurna, tidak boleh ada kesalahan atau zero accident (Mahyardiani \& Krisnatuti, 2020). Namun tidak bisa dipungkiri, kesalahan-kesalahan yang tidak disengaja dan diluar kontrol dapat saja terjadi dan memberikan dampak negatif pada rumah sakit secara keseluruhan. RSU Sarah bukanlah rumah sakit tergolong rumah sakit baru. Diketahui RSU Sarah sudah berdiri selama sepuluh tahun lebih dan sudah memberikan pelayanan pada ribuan pasiennya. Namun pada beberapa tahun belakang menghadapi masalah penurunan loyalitas pasien, kondisi tersebut diketahui dari menurunnya jumlah kunjungan pasien loyal serta menurunnya kepuasan pasien terhadap layanan yang dinikmati. Bagi sebuah rumah sakit yang berdiri lama dan sudah dikenal masyarakat, kondisi tersebut menjadi pertaruhan reputasi yang telah dibangun dengan susah payah.

Mutu pelayanan dokter dan fasilitas rumah sakit dinilai berkontribusi besar terhadap kepuasan pasien. Kepuasan pasien tersebut nantinya berdampak pada timbulnya rasa loyalitas pasien yang baik. Dokter yang memiliki daya tanggap yang baik, ramah terhadap pasien, memiliki kemampuan komunikasi dan pengendalian diri yang baik terbukti dapat meningkatkan kepuasan pasien (Chahal, 2008).

Hal yang sama juga ditemukan pada beberapa penelitian terdahulu antara lain, (Patricia, Bangun, \& Tarigan, 2018) yang menemukan adanya hubungan signifikan antara mutu pelayanan dokter dengan loyalitas pasien di Unit Rawat Jalan Rumah Sakit Siloam Manado. (Agustine \& Sulistiadi, 2019) menyebutkan dalam penelitiannya 
bahwa terdapat hubungan antara pelayanan dokter dengan loyalitas pasien kepada rumah sakit.

Selain mutu pelayanan dokter, phsical evidance juga dinilai berperan dalam loyalitas pasien. Karakteristik bangunan rumah sakit merupakan bagian dari bukti fisik yang memberikan persyaratan yang memberi nilai tambah bagi pasien. Perhatian terhadap sarana dan prasarana bangunan dan tata ruang, serta kebersihan lingkungan rumah sakit dapat mempengaruhi mood dan kesan dari pasien.

Penelitian (Debora \& Sulistiadi, 2019), menunjukkan adanya pengaruh yang signifikan antara bauran pemasaran terhadap loyalitas pasien di Rumah Sakit Awal Bros Pekanbaru. Dimana bukti fisik merupakan indikator yang memiliki nilai paling tinggi dibandingkan dengan indikator bauran pemasaran jasa lainnya yang memberikan pengaruh terhadap loyalitas pasien (Andri \& Sari, 2014).

Penelitian lainnya juga menemukan hal yang sama, bahwa elemen bukti fisik (phsical evidance) mempunyai pengaruh paling kuat terhadap loyalitas pasien diantara elemen yang lain dalam bauran pemasaran (Radfan \& Hariyanti, 2015). Hasil penelitian dari Mahendro Prasetyo Kusumo juga menemukan adanya pengaruh yang signifikan antra bangunan fisik rumah sakit terhadap loyalitas pasien rawat inap di Rumah Sakit PKU Muhammadiyah (Kusumo, 2016).

Berangkat dari fenomena dan permasalahan yang ada, penulis merasa tertarik untuk melakukan pengkajian lebih dalam lagi mengenai "Pengaruh Mutu Pelayanan Dokter dan Physical Evidance Terhadap Loyalitas Pasien Rawat Inap di RSU Sarah Medan Tahun 2020".

\section{Metode Penelitian}

Jenis penelitian yang digunakan dalam penelitian ini adalah jenis survei kuantitatif (Sugiyono, 2017), dengan menggunakan pendekatan potong lintang (cross sectional). Penelitian ini dilaksanakan di RSU Sarah. Populasi dalam penelitian ini adalah pasien umum yang menjalani rawat inap di RSU Sarah Medan. Berdasarkan hasil perhitungan dengan rumus sampel maka jumlah sampel dalam penelitian ini adalah sebanyak 82 orang. Metode pengumpulan data dalam penelitian ini melalui data primer dan sekunder dengan kuesioner dan wawancara. Adapun metode analisis data dalam penelitian ini adalah analisis univariat, bivariate, dan multivariat dengan analisis regresi logistik. 


\section{Hasil dan Pembahasan}

\section{A. Karakteristik Responden}

\section{Tabel 1}

Distribusi Frekuensi Karakteristik Pasien di RSU Sarah Medan

\begin{tabular}{clcc}
\hline No & Variabel & $\mathrm{n}$ & $\%$ \\
\hline 1 & Jenis Kelamin & & \\
& Perempuan & 48 & 58,5 \\
& Laki-laki & 34 & 41,5 \\
\hline 2 & Usia & & \\
& $\leq 40$ Tahun & 74 & 90,2 \\
& >40 Tahun & 8 & 9,8 \\
\hline 3 & Pendidikan & & \\
& SMA/Sederajat & 28 & 34,1 \\
& Perguruan Tinggi & 54 & 65,9 \\
\hline 4 & Pekerjaan & & \\
& PNS/TNI/POLRI & 22 & 26,8 \\
& Wiraswasta & 26 & 31,7 \\
& Wirausaha & 21 & 25,6 \\
& IRT & 13 & 15,9 \\
\hline No & Variabel & $\mathrm{n}$ & $\%$ \\
\hline 5 & Pendapatan & & \\
& $\quad$ R Rp. 3.000.000 & 19 & 23,2 \\
& >Rp. 3.000.000 & 63 & 76,8 \\
\hline & & &
\end{tabular}

Pada tabel 1 mengenai distribusi responden dapat diketahui bahwa dari 82 responden yang diamati, mayoritas responden berjenis kelamin perempuan yaitu ada sebanyak 48 orang $(58,5 \%)$, berumur kurang dari 40 tahun ada sebanyak 74 orang $(90,2 \%)$, jenis pekerjaan wiraswasta ada sebanyak 26 orang $(31,7 \%)$, dengan pendapatan >Rp.3.000.000 ada sebanyak 63 orang $(76,8 \%)$.

\section{B. Analisis Bivariat}

Analisis bivariat dilakukan dengan menggunakan uji Chi Square dengan tingkat kemaknaan $(\alpha)=0,05$. Adapun tujuan analisis ini untuk melihat ada tidaknya hubungan antara variabel independen (mutu pelayanan dokter dan penampilan fisik) dengan variabel dependen (loyalitas pasien). Kriteria dalam analisis ini adalah: Ho ditolak jika $\mathrm{p}<\alpha(0,05)$ maka terdapat perbedaan antara variabel independen dengan variabel dependen. Ho diterima jika $\mathrm{p}>\alpha(0,05)$ maka tidak terdapat perbedaan antara variabel independen dengan variabel dependen.

Tabel 2

\section{Hasil Analisis Chi Square}

\begin{tabular}{lc}
\hline Variabel & P value \\
\hline Mutu Pelayanan Dokter & 0,001 \\
Physical Evidance & 0,004 \\
\hline
\end{tabular}

Pada hasil analisis dengan chi square diketahui kedua variabel memiliki nilai $\mathrm{p}<\alpha$, maka dapat disimpulkan bahwa terdapat hubungan yang signifikan antara 
variabel mutu pelayanan dokter dan physical evidance dengan loyalitas pasien di RSU Sarah Medan.

\section{Analisis Multivariat}

Tahap selanjutnya setelah analisis bivariat adalah tahap multivariat. Analisis multivariat merupakan analisis yang dilakukan secara bersamaan dengan tujuan untuk mengetahui variabel independen mana yang paling mempengaruhi variabel dependen. Variabel yang dianggap mempengaruhi dalam model multivariat adalah variabel yang mempunyai $\mathrm{p}$ value $<0,05$.

Analisis multivariat yang digunakan adalah analisis regresi logistik berganda dengan model prediksi yang bertujuan untuk memperoleh model yang terdiri dari beberapa variabel independen yang dianggap terbaik untuk memprediksi terjadinya variabel dependen. Pada analisis multivariat, variabel yang masuk adalah variabel yang pada hasil bivariatnya harus memiliki nilai $\mathrm{p}<0,25$.

\section{Tabel 3}

\section{Hasil Analisis Multivariat}

\begin{tabular}{lcccccc}
\hline \multicolumn{1}{c}{ Variabel } & B & S.E & Wald & Df & p value & OR \\
\hline Mutu Pelayanan Dokter & 0,215 & 1,101 & 2,701 & 1 & 0,001 & 3,860 \\
\hline Physical Evidance & 0,421 & 1,911 & 3,001 & 1 & 0,004 & 2,995 \\
\hline
\end{tabular}

Berdasarkan tabel di atas dapat diketahui hasil analisis regresi logistik dari variabel mutu pelayanan dokter dan physical evidance terhadap tingkat loyalitas pasien. Hasil menunjukkan bahwa kedua variabel memiliki nilai $\mathrm{p}<0,05$. Hal ini bermakna bahwa kedua variabel independen berpengaruh secara signifikan terhadap variabel dependen.

\section{Pengaruh Mutu Pelayanan Dokter Terhadap Loyalitas Pasien di RSU Sarah Medan}

Hasil analisis regresi logistik menunjukkan bahwa mutu pelayanan dokter yang diberikan rumah sakit berpengaruh signifikan terhadap loyalitas pasien. Dari hasil prediksi nilai odds ratio bertanda positif sebesar 3,860. Artinya semakin baik mutu pelayanan dokter, semakin besar pula peluang peningkatan loyalitas pasien sebanyak 3,8 kali lebih tinggi bila dibandingkan dengan mutu pelayanan dokter yang tidak baik.

Salah satu cara agar penjualan jasa pelayanan satu rumah sakit lebih unggul dibandingkan para pesaingnya adalah dengan memberikan pelayanan yang berkualitas dan bermutu, yang memenuhi tingkat kepentingan pasien (Rangkuti, 2006). Salah satu jasa pelayanan yang ada di rumah sakit adalah jasa pelayanan dokter. Pelayanan dokter yang berkualitas akan mendukung hasil kualitas pelayanan rumah sakit secara keseluruhan, sehingga memberikan dampak pada loyalitas pasien (Chahal, 2008).

Secara umum bentuk layanan dokter di rumah sakit dapat diklasifikasikan menjadi layanan lini (rawat inap, rawat jalan, gawat darurat, dan tindakan operatif). Dari temuan peneliti di rumah sakit, terkait mutu pelayanan dokter di rumah sakit 
dinilai kurang baik oleh kebanyakan pasien. Hasil wawancara dengan sebagian besar pasien, menunjukkan bahwa memang dahulu mutu pelayanan dokter di rumah sakit tersebut menjadi pelayanan unggulan yang ditawarkan rumah sakit, namun dalam beberapa tahun belakangan mutu pelayanan semakin menurun. Sehingga dalam beberapa tahun terakhir jumlah kunjungan pasien ke rumah sakit tercatat terus menurun terutama pada kunjungan pasien rawat inap. Hasil ini sejalan dengan penelitian (Mohammadi \& Sohrabi, 2018); (Zulhit, Yasri, \& Abror, 2019), bahwa pelayanan dokter memiliki pengaruh secara langsung terhadap tingkat kepuasan pasien dan loyalitas pasien.

\section{E. Pengaruh Physical Evidance Rumah Sakit terhadap Loyalitas Pasien RSU} Sarah Medan

Berdasarkan hasil analisis multivariat dengan regresi logistik diperoleh bahwa phsical evidance rumah sakit berpengaruh secara signifikan terhadap loyalitas pasien di RSU Sarah Medan dengan nilai $\mathrm{p}<0,05$.

Bangunan fisik rumah sakit merupakan wujud nyata yang dapat dilihat langsung oleh pasien. Penampilan bangunan fisik rumah sakit dinilai telah mempengaruhi keputusan pasien dalam menggunakan produk yang ditawarkan. Unsur-unsur penting yang berkaitan dengan tampilan fisik suatu bangunan rumah sakit meliputi, lingkungan fisik, dalam hal ini bangunan fisik, perlengkapan, perlengkapan, logo, warna dan penampilan pegawai serta tenaga kesehatan selama bertugas di rumah sakit tersebut.

Di rumah sakit yang diteliti, mayoritas pasien menilai kebersihan ruang perawatan sangat terjaga. Kamar dilengkapi dengan fasilitas seperti tempat tidur yang nyaman dan aman, tirai yang rapi, toilet yang bersih dan AC yang berfungsi. Terlihat juga taman rumah sakit yang tertata rapi, hal ini memberikan kenyamanan bagi pengunjung.

Hasil penelitian (Mohammadi \& Sohrabi, 2018) membuktikan bahwa penampilan fisik perusahaan yang baik, juga memberikan kontribusi terhadap keputusan pelanggan yang berdampak pada peningkatan jumlah kunjungan pelanggan.

\section{Kesimpulan}

Kesimpulan menggambarkan jawaban dari hipotesis dan/atau tujuan penelitian atau temuan ilmiah yang diperoleh. Kesimpulan bukan berisi perulangan dari hasil dan pembahasan, tetapi lebih kepada ringkasan hasil temuan seperti yang diharapkan di tujuan atau hipotesis. Bila perlu, di bagian akhir kesimpulan dapat juga dituliskan halhal yang akan dilakukan terkait dengan gagasan selanjutnya dari penelitian tersebut. 
Pengaruh Mutu Pelayanan Dokter dan Physical Evidance Terhadap Loyalitas Pasien Rawat Inap

\section{BIBLIOGRAFI}

Agustine, Elisabeth Dewi, \& Sulistiadi, Wahyu. (2019). Analisis Elemen Bauran Pemasaran Yang Mempengaruhi Loyalitas Pelanggan Rumah Sakit: Systematic Review. Jurnal Administrasi Rumah Sakit Indonesia, 4(1). Google Scholar

Andri, Seno, \& Sari, Citra Cahaya. (2014). Pengaruh Bauran Pemasaran Terhadap Loyalitas Pasien di Rumah Sakit Awal Bros Pekanbaru. Riau University. Google Scholar

Arianto, Nurmin. (2017). Pengaruh Kualitas Pelayanan, Harga Dan Kepuasan Terhadap Loyalitas Pasien (Studi Kasus Pada Pasien Rawat Jalan Rumah Sakit Premier Bintaro). Jurnal Organisasi Dan Manajemen, 13(1), 1-9. Google Scholar

Chahal, Hardeep. (2008). Predicting patient loyalty and service quality relationship: a case study of civil hospital, Ahmedabad, India. Vision, 12(4), 45-55. Google Scholar

Debora, Leawaty, \& Sulistiadi, Wahyu. (2019). Hubungan Bauran Pemasaran (Marketing Mix) Dengan Loyalitas Pelanggan: Systematic Review. Jurnal Administrasi Rumah Sakit Indonesia, 5(1). Google Scholar

Kusumo, M. P. (2016). Pengaruh Faktor Bauran Pemasaran Terhadap Loyalitas Pasien Rawat Inap Rumah Sakit PKU Muhammadiyah Bantul. Jurnal Medicoeticolegal Dan Manajemen Rumah Sakit, 5(2), 107-111. https://doi.org/10.18196/jmmr.5113 Google Scholar

Mahyardiani, Ridha Rianti, \& Krisnatuti, Diah. (2020). Menguji Kepuasan Dan Loyalitas Pasien Rsia Budi Kemuliaan Menggunakan Bauran Pemasaran. Jurnal Aplikasi Bisnis Dan Manajemen (JABM), 6(1), 1. Google Scholar

Mohammadi, Morteza, \& Sohrabi, Tahmoores. (2018). Examining the Effect of Marketing Mix Elements on Customer Satisfaction with Mediating Role of Electronic Customer Relationship Management. Industrial Engineering \& Management Systems, 17(4), 653-661. Google Scholar

Patricia, Patricia, Bangun, Primsa, \& Tarigan, Malem Ukur. (2018). Pengaruh Profitabilitas, Likuiditas, dan Ukuran Perusahaan Terhadap Nilai Perusahaan Dengan Kinerja Keuangan Sebagai Variabel Intervening (Studi Empiris Pada Perusahaan Manufaktur Yang Terdaftar Di Bursa Efek Indonesia). Manajemen Bisnis Kompetensi. Google Scholar

Radfan, Nasar, \& Hariyanti, Tita. (2015). Pengaruh Bauran Pemasaran Terhadap Loyalitas Pasien di Poliklinik Paru Rumah Sakit Paru Batu. Jurnal Aplikasi Manajemen, 13(2), 220-228. Google Scholar

Rangkuti, Freddy. (2006). Measuring Customer Satisfaction: Gaining Customer Relationship Strategy (teknik mengukur kepuasan pelanggan). Jakarta: PT 
Abidah Ismail Lubis

Gramedia Pustaka Utama Sugiyono. Google Scholar

Sugiyono. (2017). Metode Penelitian Kuantitatif, Kualitatif, dan R\&D. Alfabeta: Bandung

Supriyatna, Nandang. (2016). Hubungan Kualitas Pelayanan Dan Kepuasan Dengan Kunjungan Pasien Rawat Jalan Di Upt Puskesmas Pulau Telo Kecamatan Selat Kabupaten Kapuas Kalimantan Tengah. STIE Indonesia Banjarmasin. Google Scholar

Trisnantoro, Laksono. (2018). Memahami penggunaan ilmu ekonomi dalam manajemen rumah sakit. UGM press. Google Scholar

Zulhit, Rira Amelia, Yasri, Abror, \& Abror, Abror. (2019). Influence of Marketing Mix to Customer Loyalty in Sari Anggrek Store. 2nd Padang International Conference on Education, Economics, Business and Accounting (PICEEBA-2 2018), 295-303. Atlantis Press. Google Scholar

Copyright holder:

Abidah Ismail Lubis (2022)

First publication right:

Syntax Literate: Jurnal Ilmiah Indonesia

This article is licensed under:

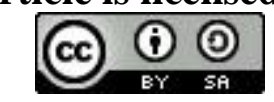

